\title{
Eight grand challenges for value sensitive design from the 2016 Lorentz workshop
}

\author{
Batya Friedman ${ }^{1} \cdot$ Maaike Harbers ${ }^{2} \cdot$ David G. Hendry ${ }^{1}$ Jeroen van den Hoven ${ }^{3} \cdot$ Catholijn Jonker $^{4,5} \cdot$ Nick Logler $^{1}$
}

Accepted: 17 February 2021 / Published online: 20 April 2021

(c) The Author(s) 2021

\begin{abstract}
In this article, we report on eight grand challenges for value sensitive design, which were developed at a one-week workshop, Value Sensitive Design: Charting the Next Decade, Lorentz Center, Leiden, The Netherlands, November 14-18, 2016. A grand challenge is a substantial problem, opportunity, or question that motives sustained research and design activity. The eight grand challenges are: (1) Accounting for Power, (2) Evaluating Value Sensitive Design, (3) Framing and Prioritizing Values, (4) Professional and Industry Appropriation, (5) Tech policy, (6) Values and Human Emotions, (7) Value Sensitive Design and Intelligent Algorithms, and (8) Value Tensions. Each grand challenge consists of a discussion of its importance and a set of tractable key questions.
\end{abstract}

Keywords Value sensitive design · Grand challenges · Design research · Power · Evaluation · Value prioritization · Appropriation $\cdot$ Tech policy $\cdot$ Human emotions $\cdot$ Intelligent algorithms $\cdot$ Value tensions

David G. Hendry

dhendry@uw.edu

Batya Friedman

batya@uw.edu

Maaike Harbers

m.harbers@hr.nl

Jeroen van den Hoven

M.J.vandenHoven@tudelft.nl

Catholijn Jonker

C.M.Jonker@tudelft.nl

Nick Logler

nlogler@uw.edu

1 The Value Sensitive Design Lab, The Information School, University of Washington, Seattle, WA, USA

2 Research Center Creating 010, Rotterdam University of Applied Sciences, Rotterdam, The Netherlands

3 Delft Design for Values Institute, Delft University of Technology, Delft, The Netherlands

4 Interactive Intelligence Group, Fac. EEMCS, Delft University of Technology, Delft, The Netherlands

5 LIACS, Leiden University, Leiden, The Netherlands

\section{Introduction}

For over one hundred years, grand challenges have successfully been used to stimulate sustained interest in fields of science and technology (Omenn 2006). Taking inspiration we, too, wanted to identify the big problems and opportunities confronting value sensitive design (VSD) (Friedman 2004; van den Hoven 2013; Davis and Nathan 2014; Friedman and Hendry 2019) and to frame them as grand challenges. Intellectually, grand challenges offer the opportunity to take stock of achievements, to consider new opportunities, and to identify and legitimate the deep questions of a field. Grand challenges should be motivating and compelling. They should be big and difficult, likely beyond the capabilities of single researchers or even single groups, but grand challenges should also be tractable such that substantial progress can be expected within 10 years.

In this article we report on the set of grand challenges that were developed at a 1-week workshop, Value Sensitive Design: Charting the Next Decade, Lorentz Center, Leiden, The Netherlands, November 14-18, 2016, organized by the special issue editors. The workshop brought together 41 senior and junior researchers from Australia, Europe, and the United States, who as a group represented the fields of civil and environmental engineering, computer science, design, digital media, ethics and technology, human-computer 
interaction, law and tech policy, library and information science, and management information systems. We sought to generate a set of grand challenges that would map out a trajectory for deepening and extending value sensitive design. The idea was that a set of well-chosen grand challenges would motivate students and academics, researchers and designers, engineers and policy makers, and would garner the support of funders and the public.

Prior to the Lorentz workshop, the value sensitive design community had been synthesizing the literature and generating possible grand challenges. In June 2015, the Value Sensitive Design Lab at the University of Washington, Seattle, U.S. wrote an unpublished report proposing eight grand challenges. In August 2015, a one-day workshop to explore research and design topics for the next decade was held at the Fifth Decennial Conference on Critical Alternatives, Aarhus, Denmark (Friedman et al. 2015). The Aarhus workshop brought together 19 researchers, many of whom would also attend the Lorentz workshop roughly 15 months later. These intellectual conversations and activities set the foundation for the Lorentz workshop.

\section{Developing the grand challenges}

Time was set aside on each day of the workshop to specifically work on grand challenges.

Day 1. On Day 1, an ideation session was conducted where workshop participants were prompted to develop some big questions for the next decade of value sensitive design. Ideas were written on Post-Its, discussed, and placed on a wall. Then, a subgroup worked together to cluster similar ideas and introduced topic headings for each of the clusters. These topic headings, along with their sticky notes, became the initial list of grand challenges.

Days 2 and 3. At the beginning of Days 2 and 3, workshop organizers reviewed the list, and used it to orient participants to the daily aims and activities of the workshop. Participants were encouraged to add new sticky notes and to comment on the headings. Thus, throughout the first three days of the workshop, participants were aware of and encouraged to actively engage with the list of emerging grand challenges. At the end of the Day 3, a preliminary list of 13 topics for grand challenges had been identified. These included: frameworks for eliciting, defining and prioritizing values; framing and addressing value tensions; stakeholders; disentangling the literature; value sensitive design and practice; value sensitive design pedagogy; evaluation and critique; value sensitive design and tech policy; application areas; accounting for power; cultural sensitivity; value sensitive design and intelligent algorithms; values and emotions.

Day 4. On Day 4 the work of developing specific grand challenges began in earnest. Participants self-organized into small groups around a subset of the topics with the charge to develop those grand challenges. Specifically, the groups spent $3.5 \mathrm{~h}$ drafting their chosen grand challenges in a standard document template, concluding with brief presentations.

Day 5. Day 5 was a half day. No explicit work was done on the grand challenges during Day 5 , however, next steps for refining and finalizing the grand challenges were discussed and put in place.

After the Workshop. In the weeks immediately following the workshop, the groups worked to refine their grand challenge write-ups, including identifying key questions. These were then submitted to the workshop organizers. In turn, the workshop organizers (in their role as editors for this special issue) lightly edited the grand challenges for consistency of format, bringing them together into this article. The lightly edited grand challenges were reviewed and revised by the original authors. The result of this process is the final set of eight grand challenges reported below.

\section{The eight grand challenges}

The following set of eight grand challenges emerged from the Lorentz workshop:

1. Accounting for Power

2. Evaluating Value Sensitive Design

3. Framing and Prioritizing Values

4. Professional and Industry Appropriation

5. Tech Policy

6. Values and Human Emotions

7. Value Sensitive Design and Intelligent Algorithms

8. Value Tensions

As noted above, these grand challenges were developed in the context of a larger community conversation about future topics for furthering value sensitive design. ${ }^{1}$ Although

\footnotetext{
1 In parallel with the reporting of the Lorentz workshop, Batya Friedman and David Hendry (2015) proposed a list of 15 grand challenges: Theory: Stakeholders; Indirect Stakeholders; Nonhuman Stakeholders; Accounting for Power; Conceptualizing Policy; Cultural Responsiveness.

Method: Eliciting Human Values; Navigating Value Tensions; Engaging with Indirect Stakeholders; Conducting Policy Analysis.

Practice: Reporting on Value Sensitive Design Projects; Skilful Practice; Professional and Industrial Appropriation; Community Resources; Beyond Information Technology: Extending to Other Domains.

Five of the Lorentz grand challenges are in this list. The three new challenges are: (1) Evaluating Value Sensitive Design, (2) Values and Human Emotions, and (3) Value Sensitive Design and Intelligent Algorithms. Accordingly, it is important to note that neither list is exhaustive. The work of synthesizing the grand challenges from these different sources is still to be done.
} 
developed in 2016, these eight grand challenges continue to be relevant for setting the agenda for current and future development in value sensitive design.

We now turn to explicate these grand challenges, for each identifying the grand challenge authors, the nature of the grand challenge, and key questions that follow.

\section{Accounting for power}

Authors: Alan Borning, Oliver Burmeister, Lisa Nathan, Åke Walldius and Till Winkler.

Value sensitive design theory and projects to date have not directly addressed the issue of power. With a few notable exceptions (e.g., Agarwal 2015), many projects have assumed that the research team's practices, organizational policies, or legal frameworks in place will support "doing the right thing," without needing to be explicit about the role and importance of power relationships.

Following in the tradition of participatory design, value sensitive design and related design approaches endeavor to include a broad range of direct and indirect stakeholder roles, those who influence and will be influenced by the processes and outcomes of design. Implicit in this scholarship is a concern for identifying, and where possible, disrupting problematic power relationships (Brey 2007).

Examples of design reinforcing problematic power relationships are found around the world in history (e.g., Foucault 1977), health (e.g., Bernoth et al.2014), urban planning (e.g., Winner 1986) and myriad other areas. Rigorous design methodologies that engage with the difference between having the power "to" and the power "over" are needed. Future scholarship needs to investigate how the distribution and exercise of power in societies is influenced by design research processes and products (e.g., evaluating the use of products, services and/or consequences of institutional interventions). Value sensitive design has the potential to help people question the role of design in the distribution and exercise of power.

Fundamentally, we are concerned that failing to address power relationships during the design research process risks limiting the ability of people, in all of their diversity, to thrive. Power relationships are ubiquitous in the diverse socio-political ecosystems humans inhabit (Young 1997, 2006) and through the following paragraphs we illustrate a few generative areas of future design scholarship.

\section{Media power}

The media, both traditional print and broadcast, as well as new media such as social media and blogs, plays a central role in the public sphere, political discourse, and governance. The current media landscape is both complex and controversial. Examples of problems include the breakdown of advertising as a revenue source for newspapers, concentration of ownership of broadcast media, the "echo chamber" effect of selective attention that leaves out other views, and the impact of fake news on political processes. At the same time, new opportunities appear through commonsbased peer production, wide scale participation, media systems that have a mixture of people-power and algorithms, micro-payment systems, and others. This is a critical time of change in the media landscape, and value sensitive design is well positioned to help design researchers conceptualize and prototype new approaches to these issues, including careful stakeholder analysis, identifying value tensions (e.g., between free speech and accountability), and designing and evaluating experimental approaches.

\section{Research process}

Conducting research is a social endeavour, which also inherently involves issues related to power (Smith 2012). In the broad field of social science, researchers decide which stakeholders are going to be heard, in which order and in what way. Also the choice of conceptual approach determines the focus of data collection and analysis, which additionally locates the power with the researcher(s) who determine what counts as "data," "findings," and "knowledge." In general, it is necessary to be aware of and understand power dynamics throughout the whole research process and find solutions to question and perhaps restructure hierarchies, or at least provide feedback mechanisms for enabling those in different positionalities to be heard.

Acknowledging the power dynamics inherent in the research endeavor is an opening for value sensitive design to reflect on its own and general research practices, including accounting for multiple stakeholders' voices, considering power dynamics within stakeholder groups and between researcher(s) and stakeholders, and identifying when forces beyond the research team make it impossible to enact the change desired.

\section{Information technology}

The digital age and especially the development of the internet, due to its originally decentralised and back-ended architecture, is often portrayed as facilitating democracy and citizen empowerment. Current developments in internet technologies, the centralization of information, cloud computing and software as a service, algorithms that make it difficult to examine and explain a result, and the automatic roll-out of updates, call such a facilitation of democracy into question.

In addition, much of the rigorous, well-funded and vetted scholarship (e.g., academic papers) is locked in databases protected by paywalls, causing a digital divide between 
people and institutions who can afford to pay for access and those who cannot. Even information that is "freely available" online often requires people to trade their personal data (knowingly or not) in order to access the information. These information juggernauts pose a serious threat for democratic discourse.

The shift towards black-boxed algorithms and programcode execution on cloud-servers, often justified with security reasons, give users access to only the front-end layer, resulting in a lack of transparency and a shift in power relations towards software and service providers. These developments in the digital realm result in a critical need for value sensitive design scholars to conceptualize and develop new design alternatives for these issues, including identifying and possibly resolving value tensions (e.g., independence and security).

We invite scholars from across the academy, including media and communications, to apply the value sensitive design approach in their research and commentaries on current issues related to considerations of power and technological design. Wider participation and explicit considerations of power will support value sensitive design scholars as they reflect on, adapt and enrich their research practice.

\section{Key questions}

- Which theories of power are well aligned for adoption or adaptation by value sensitive design?

- What are appropriate methods (either existing, or to be developed) for identifying and potentially addressing power relationships influenced by the outcomes of design?

- What are appropriate methods for identifying and potentially addressing power relationships throughout the process of design and design research?

- What types of training and support will better position design researchers to identify, articulate and take responsibility for power dynamics in their work and the outcomes of their work?

- How can value sensitive design be applied as a method for evaluation, review and exposure of power and technological relationships?

\section{Evaluating value sensitive design}

Authors: Batya Friedman and Pieter Vermaas.

Prior to value sensitive design, very little work engaged with values explicitly in the technical design process. Moreover, many claimed it could not be done. In response, at the start of its development value sensitive design provided evidence of success through "proof-of-concept" projects: where the articulation of the design process and the artifact itself constituted evidence of success. For example, the 2000-2002 work on cookies and informed consent demonstrated that a model reflecting a value in relation to technical systems could be meaningfully articulated, used to critique existing technical systems, and then used to guide future designs (Friedman et al. 2002). In this way, evaluation of value sensitive design initially consisted of demonstrating that value sensitive design is possible.

As value sensitive design matures, meaningful forms of evaluation are evolving. There is a wide range of projects - from the individual level, group level, organizational level, and societal levels that involve diverse technologies, diverse human values, and diverse ethical frameworks (Friedman et al. 2006; Friedman, Smith, et al. 2006; van denoven 2013; van Wynsberghe 2013; Davis and Natha 2014). Given such depth and diversity, the grand challenge for evaluation turns from "can this be done" to "how can this be done well" and "what are the impacts?" These questions are relevant not only for the evaluation of particular projects but also for the framework as a whole and for individual components (e.g., theoretical constructs and methods). One key community resource for enabling such evaluation research would be a stock of projects that were successful or failed, at points or as a whole. These could be employed by researchers and designers for systematic investigation. Different evaluation approaches can be imagined, drawing from design studies, humanities, participatory design, as well as from the particular situations in which the work is being conducted.

\section{Creating a stock of successful and failed value sensitive design projects}

In design research, methods and tools are often supported by a stock of case studies illustrating their use. Typically this stock consists of only successful case studies. A useful next step supporting transparency would be to include failed projects as well (e.g., Vermaas et al. 2015). Developing a well balanced and rich stock of value sensitive design projects would be an asset to the community.

\section{Evaluating individual value sensitive design projects}

Value sensitive design projects frequently identify stakeholder values and then affirm and adjust a proposed design to better support those values. Such projects can be tested for achieving this aim. If a project fails to meet this aim, either entirely or partially, the question is why. Is the failure due to the value sensitive design methods and practice in spite of their robust application? Or to other factors such as an unskillful designer, an inadequate application of the methods, a poorly framed intervention, and so forth? (See Vermaas 2016 for a general analysis.) 


\section{Evaluating the value sensitive design methodology as a whole}

The value sensitive design methodology as a whole can also be evaluated (for general validation approaches for design methods see Seepersad et al. 2006, and Blessing and Chakrabarti 2009). This may entail evaluating the approach in its entirety or key individual components (e.g., such as specific methods to engage value tensions, elicit stakeholder values). There are various ways of doing so, depending on how the overall goals are formulated. Strategies might include: (1) demonstrating that value sensitive design can deliver designs that support moral values in many kinds of projects in many different domains (e.g.,civil engineering, information and communication technology, energy, policy, social design); (2) showing that value sensitive leads to projects that stakeholders find more acceptable than standard design processes; (3) successfully applying value sensitive design to projects that previously have failed with standard design processes; and (4) convincing specific audiences that value sensitive design works.

\section{Key questions}

- What range of approaches could be employed for meaningful evaluation?

- What criteria or metrics could be employed to assess success or failure?

- Given those criteria, what counts as evidence of success and failure?

- How could a stock of value sensitive design case studies that illustrate successes and failures be developed, structured and presented so that the stock would be accessible to different audiences and communities?

- How could value requirements for value sensitive design projects be formulated, particularly to account for value tensions?

- How could value sensitive design projects be assessed for whether they realize their aims of supporting specific values?

- What strategies could be utilized to evaluate the value sensitive design approach as a whole?

\section{Framing and prioritizing values}

Authors: Ian King and Annuska Zolyomi.

How can values within a value sensitive design investigation be framed so they say and mean the same thing to all parties? What are the ethical underpinnings of a valuebased investigation? Citing some of the originating scholars of value sensitive design, "value" is defined broadly as "what a person or group of people consider important in life" (Friedman et al. 2006; Friedman et al. 2006). There is both anecdotal evidence and scholarship (Le Dantec et al. 2009; Borning and Muller 2012) that suggest "value" can be an elusive or controversial concept. This grand challenge entails creating broadly accepted language and structures to evolve the approach for framing and eliciting values. Advancing value sensitive design in this direction includes, but is not limited to, describing what a value is, how sets of values may be related in a context-relevant taxonomy, and how values may be grounded within an ethical framework.

A fundamental question is the scope of a value. Does a value require universal adoption by all human cultures to be meaningful? If a value is meaningful to a definable group of less than all persons, is a value sensitive design investigation upon that value applicable only within or potentially beyond the scope of that group? Is the import of a value somehow contingent on the numerical size of the group that adopts that value?

When designing based on values, a fundamental question arises as to whether values are universally held or culturally specific. Indeed, an agreement upon a set of universal values would add clarity to the very definition of 'values'. A prominent viewpoint of value sensitive design's stance on this question was articulated in Batya Friedman, Peter Kahn, and Alan Borning's statement that "VSD builds from the psychological proposition that certain values are universally held, although how such values play out in a particular culture at a particular point in time can vary considerably" (Friedman et al. 2006; Friedman et al. 2006). As raised by Alan Borning and Michael Muller (2012), both views of universal values and contextualized values are problematic.

If pursuing universal values, what is the starting point and who has the moral authority to establish the canonical set of values? A potential starting list of universal values related to morality and social justice was posited by Batya Friedman and Peter Kahn as: Human Welfare, Ownership and Property, Privacy, Freedom from Bias, Universal Usability, Trust, Autonomy, Informed Consent, Accountability, Identity, Calmness, and Environmental Sustainability (Friedman and Kahn 2003). Note that this list was not presented as a canonical list and certainly not a universal set but, rather, examples of commonly held values; nonetheless Christopher Le Dantec, Erika Poole, and Susan Wyche (2009) assert that this list elevates the standing of the values named therein.

If value sensitive design does adopt a list of universal values, it may or may not be a static list. For example, Oliver Burmeister, John Weckert, and Christina Williamson (2011) proposed that "freedom" be added as a core value. Their proposal was based on their empirical analysis of seniors in Australia. This example evolutionary path of values demonstrates the elusive nature of striving for universal values, not to mention the danger of imposing a set of values on others. But again, Alan Borning and Michael Muller (2012) discuss 
the problematic issues of allowing for pluralistic, contextualized values. This grand challenge calls for engagement on this apparent paradox and exposition of directions forward.

The purpose of the grand challenge is to develop shared understanding among parties to a value sensitive design investigation including researchers, implementers, policy makers, and non-experts reading an account of a value sensitive design investigation, for example in the popular press. The goal is to support practitioners and consumers of value sensitive design to the end of establishing value sensitive design as a key tool for responsible creation and understanding of technological innovation.

\section{Key questions}

- What is the role of ethical theory in the value sensitive design framework?

- How does the researcher evaluate the effectiveness of connecting value sensitive design to an ethical framework? What is the decision process to determine whether a given value sensitive design investigation benefits from or requires adoption of an ethical framework?

- How does the researcher evaluate the effectiveness of connecting value sensitive design to an ethical framework? What is the decision process to determine whether a given value sensitive design investigation benefits from or requires adoption of an ethical framework?

- What ethical theories are available that would be productive for defining values?

- Should value sensitive design commit to a particular ethical framework (e.g., universal values)?

How would adoption of a framework be decided, by whom, from which bodies of knowledge, and how would it be reflected upon over time?

How does value sensitive design address dichotomies such as: tribal v. universal; preferences $\mathrm{v}$. moral values; emotions v. abstractions; clarity v. ambiguity; design role v. stakeholder role?

How might pluralism, diversity and expansion/ enrichment of conceptualizations of values be supported in the process of adopting an ethical framework?

- How could value sensitive design better support the framing of an ethical theory (e.g., care ethics) chosen for a specific initiative? What value sensitive design framework mechanism(s) and theoretical constructs need to be adopted or modified in order to support an ethical framework? Is there a concise set of best practices (analogous to a software 'API') for asso- ciating an ethical framework with a value sensitive design conceptual investigation?

- What model can be incorporated into value sensitive design describing the impact, functions, and team member responsibilities to support an ethical framework throughout the value sensitive design process? For instance, how can an ethical framework or ethical stance be communicated, as necessary, throughout the value sensitive design process to team members and stakeholders?

- How does a researcher's epistemological stance impact their interpretation and approach to value sensitive design regarding ethical framing, discovery of values, and choice of methods?

- How can values be socialized as a portable conceptual entity, to be shared throughout the value sensitive design process, to stakeholders, across projects, and to influence those outside the value sensitive design community?

- How can the value sensitive design framework account for the transformation of values as the stakeholders' conceptualization and lived experiences of values changes? What is the impact to changing values over the course of a research initiative? Over a long period of time beyond the research project?

- What are effective methods, best practices, and measures of evaluating approaches to framing and defining values?

- What are best practices for the initial discovery of values? How can the researcher engage with stakeholders early in the project to discover values?

- Would it be beneficial for the value sensitive design community to generate a set of broad, commonly observed values that can serve as a starting spoint for discovery of stakeholders' held values?

- How might a hierarchy/taxonomy of values be developed, perhaps with composite values, priorities, and changes over time?

\section{Professional practice and industry appropriation}

Authors: Oliver Heger, Alina Huldtgren, Qinyu Li, Sarah Spiekermann and Kari Watkins.

Values need to be embedded in all engineering efforts to ensure that we create more responsible IT systems. Currently a common body of knowledge on theories and methodology is still in progress. Yet it is not sufficient for the broad uptake of moral and ethical issues by those who develop systems in practice. The core challenge is to develop general guidelines and knowledge that lead innovation teams to come up with solutions informed by value sensitive design. Three problem dimensions seem particularly relevant. The first is to optimally align value sensitive design with existing 
innovation and engineering practices so that a mutual knowledge exchange and alignment can be achieved. The second is to have concrete guidelines for every stage of system design. The third is to describe an optimal organizational and administrative context with roles and responsibilities to make value sensitive design work.

\section{Alignment with existing methods}

A core challenge is to integrate value sensitive design into established engineering processes. It is important to enrich the value sensitive design approach with established methodologies from other disciplines where rich experience is established. An example is that the engineering discipline would identify implementation alternatives in the design phase of a system and do a SWOT (Strengths-Weaknesses-Opportunities-Threats) analysis to find the right system strategy. Open issues in this context are: How to enrich existing methods with value sensitive design? Are there established practices, which could be an obstacle to conduct value sensitive design, and are there ways to overcome them? Are there general methods which can be used for different contexts and application fields?

\section{Practical value sensitive design guidelines}

A best practice catalogue is needed that can inform various available practices and application areas with theory and method. While this accumulation and aggregation of existing knowledge is necessary, there are open issues that value sensitive design currently does not yet address. For instance, how to derive and evaluate potential design options and concrete design requirements from values? A further issue is whether value sensitive design needs to be extended to include fundamental ethical analysis to open the "design space' before the actual value sensitive design work starts; this is against the background of fundamental dilemmas, such as developing secure killing machines or robots that care for the elderly. Thirdly, measuring success of value sensitive design work implies that we develop measurement instruments that go beyond monetary value only. When, to what extent, and how can we measure value creation achieved through value sensitive design?

\section{Roles and responsibilities}

There is little practical guidance yet on how to best run value sensitive design projects structurally. Roles and responsibilities need to be defined. For instance: How to integrate value sensitive design into business processes? Is there a need for a chief value officer or subject matter experts?

\section{Key questions}

- How can we embed value sensitive design with other work in computer ethics and engineering?

- What would a concrete holistic value sensitive design approach look like?

- What knowledge and experience do we have for optimal project set-up?

\section{Tech policy}

Authors: Batya Friedman and Bryce Clayton Newell.

Value sensitive design research has addressed questions that are relevant to technology and information policy. To date, technology and information policy have entered the value sensitive design research agenda in two primary ways. First, policy has been used as part of (or to inform) conceptual and technical investigations. For example, policy has been used as a tool to expand the design space and the range of possible technical solutions (e.g., Miller et al. 2007). Second, value sensitive design has been used to inform and develop policy (e.g., Friedman et al. 2006). That said, these efforts, conceptual, and methodological connections between policy and value sensitive design research remain underexplored, despite the broad possibilities that exist for policy and value sensitive design to inform each other and to significantly impact the design process, policy outcomes, and human behavior.

These open possibilities suggest the need for a grand challenge to the value sensitive design community to more directly engage policy (and policymakers) in the process of executing value sensitive design research and to explore (1) how policy can be effectively deployed within value sensitive design research as a tool or device to develop more policy-sensitive research outputs, and (2) how value sensitive design research can engage policymakers and impact the formulation of technology and information policies (at local, regional, national, or international levels). Information policy has the potential to impact politics and power relationships, and value sensitive design researchers engaging with and informing policy need to critically examine and evaluate how questions and considerations of power are implicated in their work.

\section{Conceptualizing policy within value sensitive design}

Policy is a critical part of social structure. It is also something that is designed. However, how policy fits (or should fit) into value sensitive design remains an open question. Policy impacts both design practices (and possibilities) of technological artifacts (or more broadly both the tangible and intangible outcomes of design practice). In this sense policy regulates design: It has the capacity to require or 
cultivate certain design practices and features or limitations of artifacts. Like technology, policy also enables, constrains, and regulates broader forms of human behavior. Moreover, in at least some cases, the design methods employed for value sensitive technology can also be employed to design successful value sensitive policy (e.g., Miller et al. 2007). Alternatively, given that policy is fundamentally concerned with social structure, is policy best viewed as another form of empirical investigation? Or perhaps something fundamental has been left out of the tripartite methodology and some fourth type of investigation is needed to adequately account for policy?

There is a sense in which we can think of policymaking as a form of design. The process of making policy produces value-laden products (e.g., policies, regulations, laws) that are amenable to integrating existing value sensitive design methods and theory, informed by values and technology. The development of technology policy (i.e., the policymaking process) is also accompanied with a consideration of values and moral questions. However, the relationships among value sensitive design, technology policy, and policymaking are generally understudied and undertheorized in existing value sensitive design literature. The value sensitive design community would be well-served by engaging with policy more broadly including integrating scholarship and ideas from other policy-related fields (e.g., law, regulation, political science), studying policymaking processes and/or collaborating with policymakers, publishing research in policyoriented outlets, and evaluating the impact of value sensitive design research on policy outcomes.

\section{Methods for value sensitive policy}

Independent of how policy is conceptualized within value sensitive design, the question of method remains. That is, how might existing value sensitive design methods be used in the service of policy (cf. Miller et al. 2007)? Are there policy-specific methods that could and should be developed? If so, what do these look like? Moreover, policy affecting information and computing technologies can exist at various levels (Nathan and Friedman 2010), from those that regulate the interface to those that govern the exchange of information that flows across national boundaries. Do different levels of policy require different types of value sensitive methods? If so, in what ways do they differ and how can they be developed?

\section{Engaging and impacting technology policy}

We foresee multiple ways in which value sensitive design methods and practice can and should engage with questions of technology policy and the process of making policy that impacts technological innovation and design. Technology and policy both have the capacity to regulate how people use and design technological artifacts in intended and unintended ways. Regulation, understood as "the sustained and focused attempt to alter the behaviour of others according to standards or goals with the intention of producing a broadly identified outcome or outcomes" (Black 2005, p. 11), presents clear opportunities for policy-engaged value sensitive design research, and for critically re-thinking how value sensitive design methods and theory might need to be modified or adapted to engage more successfully with building, informing, and critiquing policy (existing policy or by impacting the development of new policies) and regulations.

\section{Value sensitive design, technology policy, and power}

Regulation (including various forms of policy, law, and techno-regulation) is often driven by politics, and regulatory choices frequently impact power relationships among people, states, corporations, and other entities. When integrating policy-related considerations into value sensitive design research, researchers need to account for the ways in which existing politics and power structures impact the ways in which technologies will be designed or used, as well as whether (and how) design choices impact (e.g., complicate, reduce, increase) the balance, amount, and dynamics of power within these existing structures.

\section{Key questions}

- How can value sensitive design research and practice produce examples that can serve to broaden thinking about technology policy? How can policy discussions facilitate our ability to be critical of our own normative arguments? And how can value sensitive design bring new methods or ideas to policy discussions?

- In what ways might value sensitive design serve as a mechanism to challenge or make power structures visible, - especially those facilitated, established, or sustained by policy choices?

- How can we, as designers who engage explicitly with the relationship of values and design, impact policy in order to facilitate the work of value sensitive design? Specifically: How can designers impact policy? How can designers engage with policy scholarship, people, and ideas? How can designers engage policymakers in the research as sources of pertinent information, domain experts, and as more collaborative participants?

- From a value sensitive design perspective, is policy best viewed as another form of technology (or policy-making as a form of design)?

- How does thinking about policy-making in terms of design and vice versa re-shape either or both? 
- How can engagement with technology policy inform the methods and theories used within the value sensitive design community?

- How can policy questions and issues inform the work of value sensitive design and possibly move it forward in new directions?

\section{Values and human emotions}

Authors: Tag Alshehri, Luke Stark and Daisy Yoo.

Value sensitive design asks designers and researchers to seek out and understand the key values in a sociotechnical situation or milieu (Friedman et al. 2006; Friedman et al. 2006). While these values are often implicitly or explicitly tied up in human feelings, affects and emotions, values are often discussed and explicated in rational terms by value sensitive design scholarship. Relatively little value sensitive design work has explored the non-rational aspects of values in full (Desmet et al. 2003; Stark 2016). Yet technologies such as emotion recognition systems are increasingly ubiquitous, despite little consensus regarding how human emotions are best defined in digital systems (Boehner et al. 2005). Numerous extant public controversies surrounding the design of digital technologies, such as the role of social media platform design in enabling extremism in societies around the world, hinge on the mediation of human emotion, affect, belief, and identity (Papacharissi 2015). Investigating human emotions as a central element of value sensitive design theory and practice will provide a richer understanding of human experience, and deeper insights into pressing societal concerns (Roeser 2006).

Moreover, considering emotions in the broader constellation of human values might also prompt consideration of just what the "sensitive" in value sensitive design entails. Participants in a value sensitive design project - whether designers or users - might consciously or unconsciously avoid accessing their deeper self and how they 'feel' towards particular normative situations (Peters 2011). How can scholars and designers practice value sensitive design in a more emotionally "sensitive" manner, one that reflexively situates emotions within the broader range of human mental life?

\section{Practices and methods}

Stemming from the core question of how to account for affect, feelings, moods, emotions and emoting in the emergence of human values, we need expanded research methods and researcher practices that are sensitive to the affective and emotional components of values and their role in the design process (Desmet et al. 2007). Foregrounding the role of human emotions in human values means bringing together mixed critical methods for describing, eliciting, and understanding human emotions in the context of conceptual, empirical, and technical work (Desmet et al. 2001). In applying value sensitive design methods to exploring human emotions and their role in human values, researchers should further consider how to apply a degree of critical reflection to their own research practices around emotion: How their personal and intellectual backgrounds shape the evaluation of human emotions as legitimate sources of knowledge and expression, and how to unpack and critique their own value assumptions regarding human feeling.

\section{Key questions}

- How do we account for values vis-à-vis emotions?

- How are values grounded in non-rational (as opposed to irrational) aspects of human experience such as affect, feelings, moods, emotions and emoting?

- What is the role of emotion in judging "what people consider important in life"?

- What is the role that emotions play in shaping how values are performed and expressed in a particular context?

- What methods do we need to carry out for more emotionally "sensitive" value sensitive design?

\section{Value sensitive design and intelligent algorithms}

Authors: Jason Millar and Dave Miller.

Intelligent algorithms are making their way into big data analytic systems, smart cities and transportation, embedded devices, robots and other artificial intelligence (AI) applications. Those soon-to-be ubiquitous algorithms will be uniquely positioned to co-shape societies according to the interplay between the values they exert (embedded by designers), and the values people bring to bear in their interactions with those systems. Intelligent algorithms have several characteristics that raise unique ethical challenges. First, they will exert asymmetrical power in that small groups of people designing them will be able to affect a large number of users and interactants. Additionally, these systems can rapidly change in their behavior and capabilities, due to the ease of upgrading software (Bahler 2016; Stone 2009; Talbot 2014). Second, intelligent algorithms based on machine learning may be unpredictable by design, eroding the traditional causal link between designers and the behavior of their technologies (Millar and Kerr 2016). Third, the speed of intelligent algorithms will outpace our ability to monitor or respond to them in real time, further eroding our ability to meaningfully control them (Wallach and Allen 2009). Finally, intelligent algorithms will function within multi-agent systems of people and other intelligent algorithms which, when considered alongside the three previous characteristics, suggests they might best be analyzed as stakeholders in their own right (Kahn et al. 2011). 
In light of this list of features, some suggest that intelligent algorithms should be abandoned because they pose a unique threat to our future (Sainato 2016). Others argue that the appropriate response is to establish legal and regulatory regimes, including limits on developing certain technologies (Kerr and Szilagyi 2016), tailored to address the unique concerns raised by intelligent algorithms (Calo 2015). What seems certain is this: Whichever intelligent algorithms we pursue, with all the power they promise, they should be designed to benefit the societies in which they act, and to co-shape those societies in ways that are ethical, just, and legitimate. We therefore need a framework to aid in the evaluation and design of intelligent algorithms, one that can rise to this grand challenge of co-shaping intelligent algorithms and ourselves.

Value sensitive design is uniquely positioned to meet this challenge. Two core aspects of value sensitive design-its focus on stakeholders and on the analysis of value tensions that arise in practical use contexts - map to the unique and ethically challenging characteristics of intelligent algorithms described above. Furthermore, value sensitive design functions both as a framework for exposing and evaluating the values embedded in emerging and evolving technologies, and, importantly, as a prospective design framework for co-shaping the relationships among technologies, designers and engineers, and stakeholders (Friedman, Kahn, et al. 2006; Friedman, Smith, et al. 2006; Van Wynsberghe 2013). Thus, as a "theoretically grounded approach to the design of technology that accounts for human values in a principled and comprehensive manner throughout the design process" (Friedman et al. 2006; Friedman, Smith, et al. 2006), value sensitive design is a promising way forward. We need a deliberate framework that can help us understand what, ethically, we have done with intelligent algorithms, and how to move forward in attempts to make intelligent algorithms better. Value sensitive design appears capable of rising to this challenge.

\section{Key questions}

- How does a value sensitive design approach an analysis of value tensions in cases where asymmetric power relationships are amplified by ubiquitous intelligent algorithms?

- Can value sensitive design accommodate modeling intelligent algorithms as, say, technological stakeholders when they are embedded in multi-agent systems?

- How should technological stakeholders' values be balanced against human stakeholders' values, all other things being equal?

- How do we decide between the risk of breaking a complex "intelligent" system and allowing direct harm to some people?
- What value sensitive design methods can be developed for the purpose of evaluating intelligent algorithms based on machine learning where the traditional causal link between designers and the behavior of their technologies has been eroded?

\section{Value tensions}

Authors: Christiane Grünloh, Naomi Jacobs and Ibo van de Poel.

Value sensitive design tries to account for human values in design (Friedman, Kahn, et al. 2006; Friedman, Smith, et al. 2006). This implies accounting for the values of direct and indirect stakeholders, values of the members of the design team (such as researchers and designers) and other relevant values (such as environmental care or fairness). These values may, however, be in tension with each other and in such cases there may be no design that accounts for all relevant values equally and simultaneously.

Such value tensions may occur among the values of one person. For example, a person might value privacy as well as security and there might be no design that facilitates both values to the same extent, at the same time. Value tensions may also occur among the values of different persons (either among persons in the same stakeholder group or persons who belong to different stakeholder groups). For example, some stakeholders may value profit over sustainability, while others value sustainability over profit. Here a value tension occurs between two different values. On the other hand, tensions might also occur within one and the same value. For example, respecting the autonomy of one person may create tensions with respecting the autonomy of another person.

Value tensions may change over time. For example, due to the increased awareness of the threat of climate change and its consequences, sustainability has become a more important value today. Since the priority of values might change over time, new value tensions may arise, or the intensity of the tension may change.

Some value tensions are simply not resolvable. For example, in some cases, the value of liberty and the value of equality are incommensurable (Hsieh 2016). This possibility of what is known in philosophy as value incommensurability is, however, under conceptualized in the value sensitive design literature.

There are already methods available in the value sensitive design literature to deal with value tensions, such as Value Dams and Flows (Miller et al. 2007). However, it is useful to explore a broader range of methods, for example from the philosophy and decision theory literature (van de Poel 2015). Ethical theory can provide moral justification and help to prioritize certain values over other values (MandersHuits 2011). Making use of an ethical theory has the potential to lead to a more transparent and systematic approach to 
resolving value tensions, which could provide one means to check an over reliance on preferences of the designer or the most powerful stakeholder group.

In addition, there may be other solutions to value tensions. Sometimes the stakeholders themselves might be able to negotiate and solve the value tensions; on other occasions, it might be possible to find an innovative design solution that solves the value tension (van den Hoven et al. 2012).

\section{Key questions}

- What methods exist to deal with value tensions within as well as outside the value sensitive design literature? Can methods outside the value sensitive design literature, for example from philosophy and decision theory, enrich value sensitive design?

- Are some values incommensurable and, if so, what are the implications for dealing with such value tensions in value sensitive design?

- How can value sensitive design account for values that change over time and therefore create or alleviate value tensions?

- How can stakeholders themselves recognize and balance value tensions? And how can we, as value sensitive design practitioners, help them to do so?

- Does value sensitive design need an ethical theory to help solve value tensions? If so, who should bring in this ethical expertise and when in a value sensitive design project?

- How do we recognize the most crucial value tensions in a value sensitive design project?

- How do we prevent or deal with situations in which stakeholders fundamentally disagree with each other (for example because they have conflicting interests)? Does lifting the debate to the level of values help when negotiating between conflicting interests?

Acknowledgements We would like to thank all of the participants of the November 2016 workshop Value Sensitive Design: Charting the Next Decade hosted by the Lorentz Center, Leiden, The Netherlands for the many stimulating and thoughtful conversations that informed the development of these grand challenges.

Open Access This article is licensed under a Creative Commons Attribution 4.0 International License, which permits use, sharing, adaptation, distribution and reproduction in any medium or format, as long as you give appropriate credit to the original author(s) and the source, provide a link to the Creative Commons licence, and indicate if changes were made. The images or other third party material in this article are included in the article's Creative Commons licence, unless indicated otherwise in a credit line to the material. If material is not included in the article's Creative Commons licence and your intended use is not permitted by statutory regulation or exceeds the permitted use, you will need to obtain permission directly from the copyright holder. To view a copy of this licence, visit http://creativecommons.org/licenses/by/4.0/.

\section{References}

Agarwal, S. D. (2015). The process of networked civic innovation: Examining the role of values, resources, and power in community-based technology projects. University of Washington, Seattle, WA, USA. Retrieved from https://digital.lib.washington.edu/resea rchworks/bitstream/handle/1773/33679/Agarwal_washington_ 0250E_14561.pdf? sequence $=1$ \&isAllowed $=\mathrm{y}$

Bahler, T. (2016). Tesla has released Autopilot 8.0. Time.com (Sept. 22).

Bernoth, M., Dietsch, E., Burmeister, O. K., \& Schwartz, M. (2014). Information management in aged care: Cases of confidentiality and elder abuse. Journal of Business Ethics, 122(3), 453-460.

Black, J. (2005). What is regulatory innovation? In J. Black, M. Lodge, \& M. Thatcher (Eds.), Regulatory innovation (pp. 1-15). Edward Elgar.

Blessing, L. T. M., \& Chakrabarti, A. (2009). DRM: A design research methodology. Springer.

Boehner, K., DePaula, R., Dourish, P., \& Sengers, P. (2005). Affect: From information to interaction. In Proceedings of the 4th decennial conference on critical computing: Between sense and sensibility (CC'12) (pp. 59-68). '

Borning, A. \& Muller, M. (2012). Next steps for value sensitive design. In Proceedings of the SIGCHI conference on human factors in computing systems (pp 1125-1134). ACM Press.

Brey, P. (2007). The technological construction of social power. Social Epistemology, 22(1), 71-95.

Burmeister, O. K., Weckert, J., \& Williamson, C. (2011). Seniors extend understanding of what constitutes universal values. Journal of Information, Communication and Ethics in Society, 9(4), $238-252$.

Calo, R. (2015). Robotics and the lessons of cyberlaw. 103 California Law Review 513.

Davis, J., \& Nathan, L. P. (2014). Value sensitive design: Applications, adaptations, and critiques. In J. van den Hoven, P. E. Vermaas, \& I. van de Poel (Eds.), Handbook of ethics, values, and technological design (pp. 1-26). Springer. Retrieved from http://dx.doi. org/https://doi.org/10.1007/978-94-007-6994-6_3-1

Desmet, P. M. A., Hekkert, P., \& Hillen, M.G. (2003). Values and emotions; an empirical investigation in the relationship between emotional responses to products and human values. Applied research, practice based research: case studies, 1-9.

Desmet, P. M. A., Overbeeke, C. J., \& Tax, S. J. E. T. (2001). Designing products with added emotional value; development and application of an approach for research through design. The Design Journal, 4(1), 32-47.

Desmet, P. M. A., Porcelijn, R., \& Van Dijk, M. B. (2007). Emotional design; Application of a research-based design approach. Springer Science + Business Media B.V.

Foucault, M. (1977). Discipline and punish: The birth of the prison. Pantheon Books.

Friedman, B. (2004). Value sensitive design. In W. S. Bainbridge (Ed.), Encyclopedia of human-computer interaction (pp. 769-774). Berkshire Publishing Group.

Friedman, B., \& Hendry, D. G. (2019). Value sensitive design: Shaping technology with moral imagination. MIT Press.

Friedman, B., Hendry, D. G., Huldtgren, A., Jonker, C., Van den Hoven, J., \& Van Wynsberghe, A. (2015). Charting the next decade for value sensitive design. Aarhus Series on Human Centered Computing, 1(1), 9-10.

Friedman, B., Howe, D. C., \& Felten, E. (2002). Informed consent in the Mozilla browser: Implementing value-sensitive design. In Proceedings of the thirty-fifth annual Hawai'i international conference on system sciences. Abstract, p. 247; CD-ROM of full-paper, OSPE101. IEEE Computer Society. 
Friedman, B., \& Kahn, P. H., Jr. (2003). Human values, ethics, and design. The human-computer interaction handbook: Fundamentals, evolving technologies and emerging applications (pp. 1177-1201). Lawrence Erlbaum.

Friedman, B., Kahn, P. H., Jr., \& Borning, A. (2006a). Value sensitive design and information systems. In P. Zhang \& D. Galletta (Eds.), Human-computer interaction in management information systems: Foundations (pp. 348-372). M. E. Sharpe.

Friedman, B., Smith, I., Kahn, P. H. Jr., Consolvo, S., \& Selawski, J. (2006). Development of a privacy addendum for open source licenses: Value sensitive design in industry. In P. Dourish \& A. Friday (Eds.), UbiComp 2006: Ubiquitous computing (pp. 194211). Springer. Retrieved from http://doi.org/https://doi.org/10. 1007/11853565_12

Hsieh, N. (2016). Incommensurable values. In E. N. Zalta (Ed.), The Stanford encyclopedia of philosophy. Retrieved from http://plato. stanford.edu/archives/spr2016/entries/value-incommensurable/. https://doi.org/https://doi.org/10.1162/DESI_a_00354

Kahn, P. H. Jr., Reichart, A. L., Gary, H. E., Kanda, T., Ishiguro, H., Shen, S., Ruckert, J. H., \& Gill, B. (2011). The new ontological category hypothesis in human-robot interaction. Proceedings of the 6th International Conference on Human-Robot Interaction (pp. 159-160).

Kerr, I., \& Szilagyi, K. (2016). Asleep at the switch? How killer robots become a force multiplier of military necessity. In R. Calo, M, Froomkin, and I. Kerr (Eds.). Robot law (pp. 333-366). Edward Elgar Press. https://doi.org/https://doi.org/10.4337/9781783476 732.00023

Le Dantec, C. A., Poole, E. S., \& Wyche, S. P. (2009). Values as lived experience: Evolving value sensitive design in support of value discovery. In Proceedings of the SIGCHI conference on human factors in computing systems (pp. 1141-1150). ACM Press.

Manders-Huits, N. (2011). What values in design? The challenge of incorporating moral values into design. Science and Engineering Ethics, 17, 271-287. https://doi.org/10.1007/s11948-010-9198-2

Millar, J., \& Kerr, I. (2016). Delegation, relinquishment, responsibility: The prospect of expert robots. In R. Calo, M. Froomkin, \& I. Kerr (Eds.), Robot law (pp. 102-130). Edward Elgar Press.

Miller, J. K., Friedman, B., Jancke, G., \& Gill, B. (2007). Value tensions in design: The value sensitive design, development, and appropriation of a corporation's groupware system. In Proceedings of the 2007 International ACM conference on supporting group work (pp. 281-290). ACM Press. https://doi.org/https://doi. org/10.1145/1316624.1316668

Nathan, L. P., \& Friedman, B. (2010). Interacting with policy in a political world: Reflections from the voices from the Rwanda Tribunal project. interactions, 17(5), 56-59. https://doi.org/https:// doi.org/10.1145/1836216.1836231

Omenn, G. S. (2006). Grand challenges and great opportunities in science, technology, and public policy. Science, 314, 1696-1704.

Papacharissi, Z. (2015). Affective publics: Sentiment, technology, and politics. Oxford University Press.

Peters, C. (2011). Emotion aside or emotional side? Crafting an "experience of involvement" in the news. Journalism, 12, 297-316. https://doi.org/10.1177/1464884910388224
Poel, I. van de (2015). Conflicting values in design for values. In J. van den Hoven, P. E. Vermaas, I. van de Poel (Eds.) Handbook of ethics, values, and technological design (pp. 89-116). Springer. http://dx.doi.org/https://doi.org/10.1007/978-94-007-6994-6_5-1

Roeser, S. (2006). The role of emotions in judging the moral acceptability of risks. Safety Science, 44(8), 689-700.

Sainato, M. (2016, August 19). Stephen Hawking, Elon Musk, and Bill Gates warn about artificial intelligence. Observer.com.

Seepersad, C. C., Pedersen, K., Emblemsvåg, J., Bailey, R., Allen, J. K., \& Mistree, F. (2006). The validation square: How does one verify and validate a design method? In K. E. Lewis, W. Chen, \& L. C. Schmidt (Eds.), Decision making in engineering design (pp. 303-313). ASME.

Smith, L. T. (2012). Decolonizing methodologies: Research and indigenous peoples ( $2 \mathrm{nd}$ ed.). Zed Books.

Stark, L. (2016). The emotional context of information privacy. The Information Society, 32(1), 14-27.

Stone, B. (2009, July 17). Amazon erases Orwell books from Kindle. The New York Times.

Talbot, D. (201, July 1). Facebook's emotional manipulation study is just the latest effort to prod users. MIT Technology Review.

van den Hoven, J. (2013). Value sensitive design and responsible innovation. In R. Owen, J. Bessant, \& M. Heintz (Eds.), Responsible innovation (pp. 75-83). Wiley.

van den Hoven, J., Lokhorst, G., \& van de Poel, I. (2012). Engineering and the problem of moral overload. Science and Engineering Ethics, 18, 143-155. https://doi.org/10.1007/s11948-011-9277-z

Vermaas, P. E. (2016). A logical critique of the expert position in design research: Beyond expert justification of design methods and towards empirical validation. Design Science, 2, e7.

Vermaas, P., Dorst, K., \& Thurgood, C. (2015). Framing in design: A formal analysis and failure modes. In Proceedings of the 20th International Conference on Engineering Design (ICED15), 3, 133-142. The Design Society.

Wallach, W., \& Allen, C. (2009). Moral machines: Teaching robots right from wrong. Oxford University Press.

Winner, L. (1986). Do artifacts have politics? In L. Winner (Ed.), The whale and the reactor: A search for limits in an age of high technology (pp. 19-39). University of Chicago.

van Wynsberghe, A. (2013). Designing robots for care: Care-centered value-sensitive design. Science and Engineering Ethics, 19(2), 407-433.

Young, I. M. (1997). Asymmetrical reciprocity: On moral respect, wonder, and enlarged thought. Constellations, 3(3), 340-363.

Young, I. M. (2006). Responsibility and global justice: A social connection model. Oxford University Press.

Publisher's Note Springer Nature remains neutral with regard to jurisdictional claims in published maps and institutional affiliations. 